\title{
Influence of Secondary Structure on Electronic Energy Relaxation in Adenine Homopolymers
}

Carlos E. Crespo-Hernández and Bern Kohler*

Department of Chemistry, The Ohio State University, 100 West 18th Avenue, Columbus, Ohio 43210.

Supporting Information 


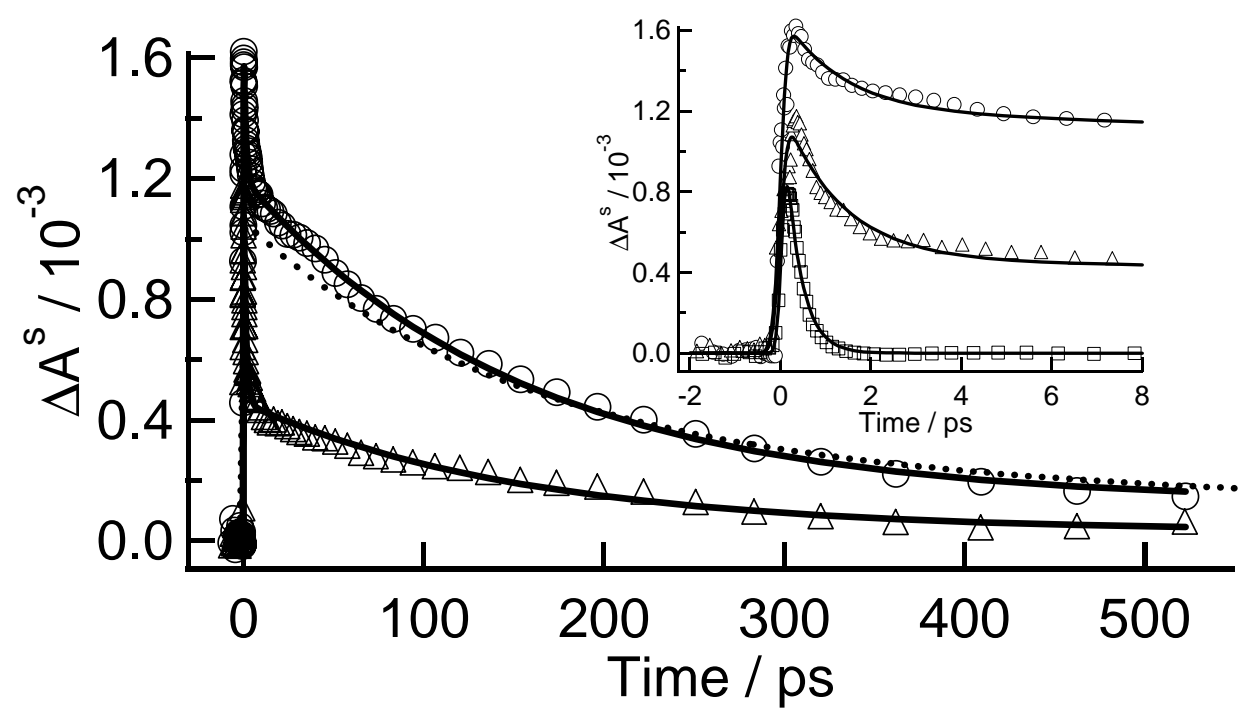

Figure S1. Transient absorption signals from poly(A) (triangles) and poly(dA) (circles) at $570 \mathrm{~nm}$ in back-to-back experiments at neutral $\mathrm{pH}$. Solid curves are from fits, while the dashed curve is the fit to the emission decay at $340 \mathrm{~nm}$ reported in ref 19 for the oligonucleotide $(\mathrm{dA})_{15}$. The inset provides a short time view of the polyadenylate data along with data from AMP (squares). 


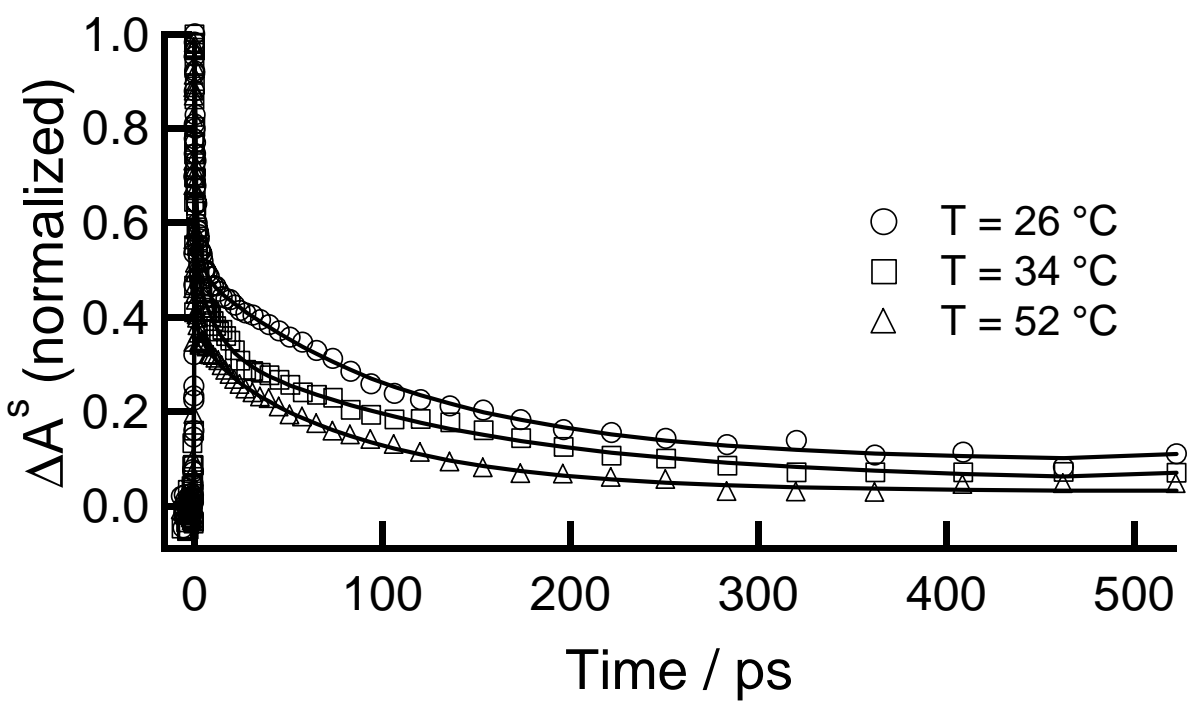

Figure S2. Transient absorption at $570 \mathrm{~nm}$ following UV excitation of poly(A) at the indicated temperatures. The signals have been normalized. 